\title{
PENGARUH MEDIA SOSIAL TERHADAP CITRA MEREK DAN NIAT BELI
}

\section{INFLUENCE OF SOCIAL MEDIA ON BRAND IMAGE AND BUYING INTENTION}

\author{
Natalia Suwarsih $^{1^{*}}$, Theresia Gunawan ${ }^{2}$, Istiharini ${ }^{3}$ \\ Universitas Katolik Parahyangan ${ }^{1,3}$, Universitas Katolik Parahyangan ${ }^{2}$ \\ 7193.nat@gmail.com ${ }^{1}$
}

\begin{abstract}
Currently half of the world's population uses various social media platforms, so social media is a source of commercial activity. This study aims to determine the effect of social media marketing on brand image on purchase intention of generation $Z$ at a university with brand image as a mediation variable. The method used in this research is to use descriptive quantitative analysis, descriptive that is to explain, analyze and find out the value of a variable against other variables. While the quantitative research method is to examine the population or sample where the sample is taken randomly to collect data with research instruments to test a hypothesis. The results of this study are that there is a positive effect of social media marketing on brand image, there is a positive effect of brand image on purchase intention of generation $Z$, there is a positive effect of social media marketing on purchase intention of Generation $Z$, and there is also a positive influence of social media on generation $Z$ purchase intentions by mediating brand image
\end{abstract}

Keywords: Social Media Marketing, Brand Image, Purchase Intention, Generation Z

\begin{abstract}
ABSTRAK
Saat ini setengah dari populasi dunia menggunakan berbagai platform media sosial, sehingga media sosial menjadi sumber kegiatan komersial. Penelitian ini bertujuan untuk mengetahui pengaruh pemasaran media sosial terhadap citra merek terhadap niat beli generasi $\mathrm{Z}$ pada sebuah universitas dengan variabel citra merek sebagai mediasi. Metode yang digunakan dalam penelitian ini adalah menggunakan analisis deskriptif kuantitatif, deskriptif yaitu untuk menjelaskan, menganalisa dan mengetahui nilai suatu variabel terhadap variabel lainnya. Sedangkan metode penelitian kuantitatif untuk meneliti populasi atau sampel dimana sampel diambil secara random untuk mengumpulkan data dengan instrumen penelitian untuk menguji suatu hipotesis. Hasil dari penelitian ini adalah terdapat pengaruh positif dari pemasaran media sosial terhadap citra merek, terdapat pengaruh positif dari citra merek terhadap niat beli generasi $\mathrm{Z}$, terdapat pengaruh positif dari pemasaran media sosial terhadap niat beli generasi $Z$, dan juga terdapat pengaruh positif dari media sosial terhadap niat beli generasi $\mathrm{Z}$ dengan mediasi citra merek
\end{abstract}

Keywords: Pemasaran Media Sosial, Citra Merek, Purchase Intension, Generasi Z 


\section{PENDAHULUAN}

Persaingan mendapatkan siswa untuk melanjutkan jenjang pendidikan tinggi tidak hanya dilakukan oleh perguruan tinggi negeri tetapi juga oleh perguruan tinggi swasta (Sudarwati \& Tikwalau, 2014). Selain menawarkan program pendidikan yang dirasakan sesuai bagi kemampuan dan keinginan para siswa, perguruan tinggi swasta bersaing dari berbagai macam faktor.

Salah satu faktor yang biasa digunakan yaitu faktor promosi. Untuk menentukan jenis promosi yang sesuai untuk perguruan tinggi, terlebih dahulu diperlukan informasi mengenai sasaran promosi, tujuan promosi, rancangan pesan, dan media promosi (Sudarwati \& Tikwalau, 2014). Salah satu jenis media promosi yaitu pemasaran media sosial. Konsep media sosial, yang merupakan situs jejaring sosial atau social network seperti Facebook, Twitter, Flickr dan Blog, telah menjadi salah satu faktor penting dalam bisnis (Miller, 2009). Aplikasi media sosial dalam kategori social network yang paling banyak digunakan adalah youtube lalu selanjutnya Facebook, Twitter, dan Instagram. Aplikasi tersebut saat ini banyak yang berfungsi sebagai media komunikasi untuk promosi. Banyak kalangan usaha menggunakan media komunikasi ini untuk dimanfaatkan (Aklani, 2016).

Penggunaan media sosial sangat tepat untuk dilakukan karena menurut kemkoninfo, pengguna internet di Indonesia mencapai 63 juta orang dan $95 \%$ dari jumlah tersebut menggunakan aplikasi jejaring sosial. Situs jejaring sosial yang paling banyak di akses oleh warga negara Indonesia adalah Facebook dan Twitter (kominfo.go.ia., 2013). Gambar 1 dibawah ini menunjukkan jumlah penggunaan media sosial di Indonesia pada tahun 2019 menurut globalwebindex:

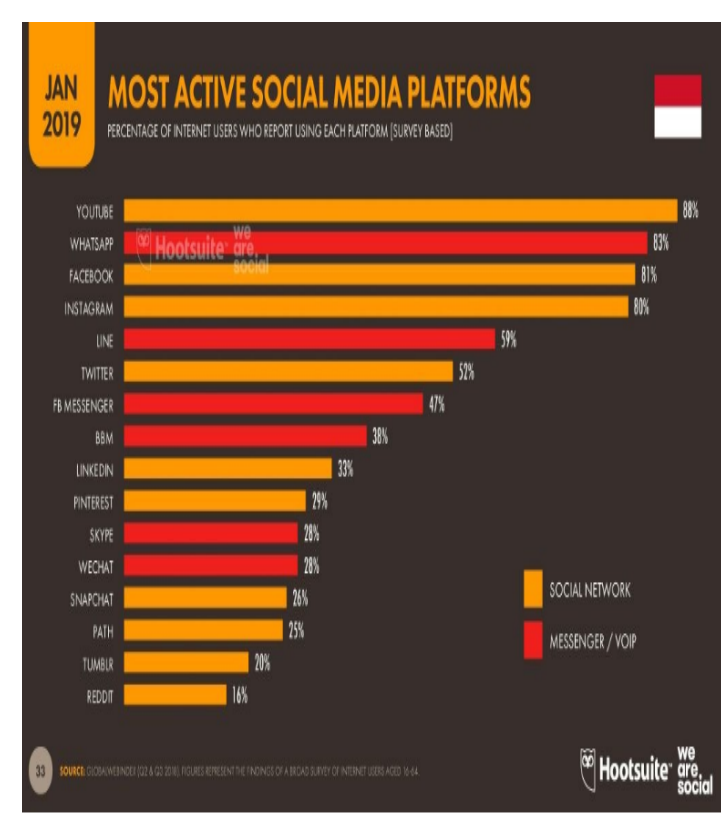

Gambar 1 Most Active Media sosial Platforms in Indonesia

Sumber: globalwebindex (2019)

Saat ini setengah dari populasi dunia menggunakan berbagai platform media sosial, sehingga media sosial menjadi sumber kegiatan komersial. Platform media sosial biasa digunakan untuk memperkuat identitas suatu merek, kegiatan ini juga dapat meningkatkan kepercayaan konsumen terhadap merek tersebut, sehingga (Kurcova et al., 2019). Pemasaran media sosial akan berdampak pada brand produk yang sedang di promosikan (Angkie, 2019). Menurut Van Dijk (2006) hal paling penting yang didapatkan melalui sistem pemasaran media sosial yaitu untuk menguatkan citra suatu merek.

Citra suatu merek akan memperkuat persepsi yang dimiliki konsumen mengenai produk sebagai hasil dari refleksi pemikiran konsumen tersebut (Kotler, P., \& Keller, 2016). Sehingga image yang terbentuk di dalam suatu objek akan lebih kuat dan lebih baik lagi jika penyampaian promosi melalui pemasaran media sosial dilakukan dengan tepat (Kotler, P., \& Keller, 2016). 
Menurut Schivinski, B., dan Dabrowski (2014) penelitian mengenai pengaruh media sosial yang digunakan sebagai alat komunikasi pada organisasi untuk mempengaruhi citra merek masih kurang. Penelitian ini dibutuhkan karena merupakan bentuk komunikasi yang dipakai dan dikontrol oleh organsisasi itu sendiri untuk mendapat keefektifan dari penggunaan alat komunikasi tersebut.

untuk penelitian yaitu untuk
menyelidiki efek dari komunikasi media sosial yang dibuat pengguna dengan menerapkan berbagai strategi dalam membuat konten media sosial (Castronovo \& Huang, 2012; Mangold \& Faulds, 2009; X. Wang et al., 2012; Winer, 2009). hingga saat ini sangat sedikit penelitian yang meneliti perbedaan efek komunikasi media sosial terhadap citra merek. Diperkuat dengan gagasan hasil penelitian oleh Kurcova et al. (2019) yang memberi saran bagi praktisi pemasaran tentang jaringan media sosial mana yang harus difokuskan saat melakukan investasi media sosial.

Berdasarkan latar belakang di atas, penulis tertarik untuk mengkaji pengaruh pemasaran media sosial terhadap citra merek dan terhadap niat beli pada generasi $\mathrm{Z}$ dengan variabel citra merek sebagai mediasi.

Media sosial adalah kumpulan online platform dan alat komunikasi yang digunakan orang untuk berbagi konten, profil, pendapat, pengalaman, dll., dan dirancang untuk memfasilitasi percakapan online dan interaksi di antara kelompok orang. Media sosial adalah platform komunikasi. Dominasi teknologi 2.0 dan media sosial telah mengarahkan pengguna internet untuk terus menggunakan jaringan online. Salah satu yang paling penting adalah social network (jejaring sosial)
(Schivinski, B., \& Dabrowski, 2014). Jejaring sosial adalah tindakan menghubungkan sosial platform media. Menurut Chauhan dan Pillai (2013) jejaring sosial melalui media online dapat dipahami sebagai beragam sumber informasi digital yang dibuat, diinisiasi, diedarkan, dan dikonsumsi oleh pengguna internet sebagai cara untuk saling memberikan informasi tentang produk, merek, layanan, kepribadian dan masalah. Jejaring sosial atau social network adalah situs yang menggunakan satu atau lebih instrumen media sosial untuk menyediakan konektivitas, interaksi, komunikasi, dan pertukaran informasi antar orang (Simon, 2010). Boyd dan Ellison (2007) mendefinisikan situs jejaring sosial sebagai layanan berbasis web yang memungkinkan individu untuk: 1) membangun profil publik atau semipublik dalam sistem terikat, 2) mengartikulasikan daftar pengguna lain yang mereka bagikan koneksi, dan 3) melihat dan melintasi daftar koneksi mereka dan yang dibuat oleh orang lain dalam sistem.

Pemasaran media sosial adalah kegiatan organisasi dalam menggunakan media sosial untuk menarik pengunjung ke halaman atau situs resmi perusahannya. Sehingga para pengunjung dapat melihat informasi yang tersedia dalam situs tersebut. Informasi yang disediakan biasanya mengenai produk baru, pencapaian ataupun promosi (Khan \& Jan, 2015).

Saat ini media sosial sangat memengaruhi setiap bidang kehidupan karena merupakan bentuk komunikasi baru dan juga memengaruhi keputusan pembelian (Pongpaew et al., 2017). Platform media sosial menawarkan keterlibatan pengguna tetap dalam agenda pemasar. Saat ini, merek mencoba mengelola serangkaian proses yang dimulai dari penciptaan identitas 
di jejaring sosial, blog, dan alat digital lainnya dan melanjutkan dengan layanan pelanggan dalam kerangka pemasaran media sosial (Kircova et al., 2015). Oleh karena itu, keterlibatan konsumen saat ini berarti pengalaman konsumen di platform media sosial dan sesuai dengan refleksi keadaan psikologis mereka (Kırcova et al., 2019).

Dari semua media sosial, situs jejaring sosial seperti Facebook, Twitter dan YouTube mungkin telah menghasilkan publisitas terbanyak di antara akademisi dan komunikasi lainnya. Selanjutnya, media sosial menjadi saluran yang memfasilitasi komunikasi konsumen ke konsumen dan mempercepat komunikasi di antara konsumen (Duan et al., 2008).

Instagram adalah cara cepat, indah, dan menyenangkan untuk berbagi foto dengan teman dan keluarga. Sebagai cara kerja yang melibatkan langkah-langkah berikut: mengambil gambar, pilih filter untuk mengubah tampilannya dan kemudian kirimkan ke Instagram. Juga, gambar dapat dibagikan di Facebook, Twitter, Tumblr. Instagram pertama kali diperkenalkan sebagai aplikasi perangkat lunak untuk iPhone pada Oktober 2010 dan pada April 2012 di pasar sistem operasi Android. Pada September 2012, Facebook membeli Instagram seharga satu miliar dolar. Instagram sekarang memiliki 90 juta pengguna aktif bulanan. Aplikasi ini memungkinkan penggunanya untuk mengekspresikan diri melalui foto. Untuk menggunakan Instagram diperlukan perangkat yang berfungsi sebagai sistem operasi seperti Android atau iOS (Apple). Instagram tidak tersedia di perangkat Windows atau Blackberry.

Media sosial semakin menjadi bagian dari kehidupan, penelitian membuktikan bahwa hal tersebut mempengaruhi keputusan pembelian bersama dengan kebutuhan sosialisasi sehari-hari. Berbagai penelitian menunjukkan bahwa media sosial menjelaskan 18\% hingga $79 \%$ social commerce (Abed et al., 2015). Penelitian oleh Kim dan Park (2013) menemukan bahwa kepercayaan pada media sosial menjelaskan $33 \%$ niat pembelian social commerce. Studi lain menentukan bahwa risiko komersial dan kepercayaan yang dirasakan di situs web menjelaskan 54\% dari niat pembelian social commerce (Farivar et al., 2017).

Keller (2009) menyatakan bahwa citra merek adalah persepsi umum terhadap suatu merek yang muncul di memori konsumen dan merupakan memori yang di kombinasi dengan semua merek yang di ingat. Oleh karena itu citra merek merupakan komponen pemasaran utama. Menurut (Kotler, 2004), merek adalah nama, istilah, tanda, simbol, desain, atau kombinasi dari hal-hal ini, yang dimaksudkan untuk mengidentifikasi barang atau layanan dari seseorang atau sekelompok penjual dan untuk membedakannya dari produk pesaing. Merek bertindak sebagai pengaruh penting pada keputusan pembelian dan juga dapat mempengaruhi keputusan pembeli untuk membayar dengan harga premium walaupun jenis produknya sama (Lin, C. T., \& Shii, 2018). Berdasarkan Palmer Adrian (2001) merek sangat penting karena dapat mendorong pembeli untuk memilih produk atau jasanya dibandingkan denan produk atau jasa lainnya yang serupa.

Citra merek adalah struktur fisik yang terbentuk dalam benak konsumen. Citra merek adalah sebuah kombinasi perasaan konsumen terhadap produk itu sendiri dan faktor tidak langsung yang 
terkait. Singkatnya, citra merek adalah makna suatu merek diterima melalui organ indera konsumen (Seo \& Park, 2018). Citra merek didefinisikan sebagai jumlah total asosiasi merek yang dimiliki oleh memori konsumen yang mengarah pada persepsi tentang merek. Asosiasi dari citra merek bersifat multidimensi dan terdiri dari dimensi afektif atau sikap terhadap merek dan dimensi kualitas yang dirasakan (K. Keller, 2003).

Niat pembelian adalah semacam pengambilan keputusan tetapi mempelajari alasan terlebih dahulu untuk membeli atau memilih merek tertentu oleh konsumen (Shah, 2012). Morinez et al. (2007) mendefinisikan niat beli sebagai situasi di mana konsumen cenderung membeli produk tertentu secara pasti. Keputusan pembelian pelanggan adalah hal yang kompleks. Niat pembelian biasanya terkait dengan perilaku, persepsi dan sikap konsumen. Perilaku pembelian adalah poin utama bagi konsumen mengakses dan mengevaluasi produk tertentu. Ghosh (1990) menyatakan bahwa niat beli adalah alat efektif untuk memprediksi proses pembelian. Niat pembelian mungkin diubah di bawah pengaruh harga atau persepsi kualitas dan nilai. Selain itu, konsumen juga terpengaruh oleh motivasi internal atau eksternal selama pembelian proses (Gogoi, 2013). Para peneliti telah mengusulkan enam tahap sebelum memutuskan untuk membeli produk, yang adalah: kesadaran, pengetahuan, niat, preferensi, persuasi dan pembelian (Kawa et al., 2013; Kotler \& Armstrong, 2010). Pelanggan selalu berpikir begitu membeli dengan harga termurah, pengemasan sederhana dan produk kecil merupakan risiko tinggi karena kualitasnya produk-produk ini tidak dapat dipercaya (Gogoi, 2013).
Umumnya merek adalah nama dan simbol. Hal tersebut merupakan alat penting untuk menciptakan citra positif di mata pelanggan. Merek memiliki peran yang sangat penting dalam menciptakan loyalitas pelanggan dan mempertahankan pangsa pasar perusahaan. Pelanggan setia loyal terhadap merek, melakukan pembelian kembali dan merekomendasikan merek kepada orang lain. Dalam penelitian sebelumnya, hubungan antara Brand Equity dan niat beli konsumen menyatakan terdapat hubungan signifikan antara Brand Equity dan kemauan untuk merekomendasikan pembelian merek kepada orang lain (Ajini, 2012). Sebagian besar penelitian sebelumnya menguji pengaruh citra merek pada niat beli konsumen dan menunjukkan hubungan yang signifikan antara keduanya variabel (Arslan \& Altuna, 2010; Chi et al., 2009; Tariq et al., 2013). Zeeshan (2013) dalam studinya menemukan itu citra merek memiliki pengaruh signifikan terhadap pembelian niat pria. Divolf (2005) menyatakan bahwa ada lebih banyak kemungkinan brand awareness yang tinggi mengarah pada merek yang tinggi asosiasi di benak pelanggan. Karena itu, lebih mungkin bahwa brand awareness mengarah ke peningkatan keputusan konsumen untuk membeli merek tersebut (Tih \& Lee, 2013). Hasil dari Küster dan Hernández (2012) juga menyarankan bahwa sikap terhadap merek memiliki dampak signifikan terhadap niat beli mereka. (Kawa et al., 2013) dalam penelitian mereka menunjukkan bahwa merek memiliki dampak signifikan terhadap keputusan pembelian pelanggan.

Penelitian milik Kim, D. J., Ferrin, D. L., \& Rao, (2008) menyatakan konsumen membuat keputusan pembelian berdasarkan niat beli (intention). Niat konsumen tersebut 
dipengaruhi olehnya persepsi manfaat, risiko (risk), dan kepercayaan (trust) terhadap entitas penjual. Konsumen akan lebih mungkin untuk melakukan pembelian ketika risiko yang dirasakan rendah, ketika manfaat yang dirasakan tinggi, dan ketika kepercayaan tinggi (efek langsung). Kepercayaan konsumen terhadap pihak penjual atau entitas juga akan meningkatkan niatnya untuk membeli secara tidak langsung dengan mengurangi miliknya persepsi risiko (efek tidak langsung).

Niat beli terbentuk melalui beberapa tahapan (Ferdinand, 2007). Pertama melalui aspek kognitif. Aspek kognitif adalah tahapan dimana keyakinan seseorang terhadap suatu objek yang didasari dengan kesadaran dan pengetahuan orang tersebut terhadap objek atau fenomena. Pembeli akan mengumpulkan berbagai informasi yang dibutuhkan sebelum melakukan pembelian. Aspek kedua yaitu Afektif, yang merupakan perasaan seseorang terhadap objek yang didasari pada preferensi. Pada tahap ini biasanya merupakan hasil dari evaluasi informasi yang telah didapatkan sebelumnya, dan merubahnya menjadi suatu perasaan positif atau negatif. Aspek ketiga merupakan behavior. Aspek behavior merupakan keinginan seseorang untuk berperilaku terhadap suatu objek. Behavior mengacu pada perilaku pembelian yang asalnya berupa niat beli dengan tahap kecenderungan utnuk mengambil tindakan sebelum keputusan untuk membeli produk dilaksanakan.

Dalam beberapa tahun terakhir definisi generasi telah berkembang, salah satunya adalah definisi oleh Kupperschmidt (2000) yang mengatakan bahwa generasi adalah sekelompok individu yang mengidentifikasi kelompok berdasarkan tahun kelahiran, usia, lokasi, dan peristiwa dalam kehidupan kelompok individu yang memiliki pengaruh signifikan dalam fase pertumbuhan mereka. Terdapat lima generasi berbeda diidentifikasi di dunia modern (Cilliers, 2017): 1) kaum tradisionalis (Generasi Senyap atau Generasi Terbesar), lahir antara 1928 dan 1944, 2) generasi Baby Boomer, lahir antara 1945 dan 1965, yang cenderung gila kerja, 3) generasi X, lahir antara 1965 dan 1979, generasi yang nyaman dengan otoritas dan melihat keseimbangan kehidupan kerja sebagai hal yang penting, 4) generasi Y, lahir antara 1980 dan 1995 dan yang umumnya tumbuh dalam kemakmuran dan cerdas dalam ilmu teknologi, 5) generasi Z, lahir setelah 1995.

Untuk pemahaman yang lebih baik tentang Generasi $\mathrm{Z}$ dan digitasi, harus disorot bahwa mereka lahir pada 1990-an dan dibesarkan pada 2000-an selama tahun tersebut perubahan paling mendalam di abad yang ada di dunia dengan munculnya web, internet, ponsel pintar, laptop, jaringan dan media digital yang tersedia secara bebas (Singh \& Dangmei, 2016). Ada pendapat bahwa generasi $Z$ akan menghabiskan masa muda dan dewasa mereka tahun di era pembaruan ekonomi dan sosial (Sidorcuka \& Chesnovicka, 2017). Para ahli menyoroti fakta bahwa Generasi Z dapat berfungsi baik di dunia nyata maupun virtual. Mereka dapat dengan mudah beralih di antara dua dunia ini, karena mereka menganggap mereka sebagai pelengkap bagi satu sama lain (Żarczyńska-Dobiesz \& Chomątowska, 2014).

Konsekuensi dari keadaan tersebut adalah Generasi $\mathrm{Z}$ dapat dengan mudah memeriksa sumber dan informasi yang mereka butuhkan. Mereka juga cepat berbagi informasi dengan orang lain. Komunikasi yang berlangsung di antara mereka berjalan kontinu, karena mereka menggunakan 
berbagai macam perangkat komunikasi atau media sosial (Dolot, 2018). Pemahaman tersebut sejalan dengan penelitian ini yang mengkai penggunaan media sosial sebagai sarana promosi UNPAR dengan target calon mahasiswa yang termasuk dalam kategori generasi $\mathrm{Z}$.

\section{METODE PENELITIAN}

\begin{abstract}
Jenis penelitian yang dilakukan menggunakan analisis deskriptif kuantitatif. Analisis deskriptif digunakan untuk menjelaskan, menganalisa dan mengetahui nilai suatu variabel terhadap variabel lainnya. Sedangkan metode penelitian kuantitatif dilakukan berlandaskan filsafat positivism, untuk meneliti populasi atau sampel dimana sampel diambil secara random untuk mengumpulkan data dengan instrumen penelitian untuk menguji suatu hipotesis (Sugiyono, 2009).
\end{abstract}

\section{Generasi $Z$ Calon Mahasiswa UNPAR}

Populasi penelitian yaitu Generasi $Z$ yang merupakan siswa atau siswi SMA atau SMK sederajat di Kota Bandung yang berjumlah 122.828, dengan kisaran umur antara 15 sampai dengan 18 tahun. Penelitian ini merupakan penelitian deskriptif sehingga menurut (Fraenkel et al., 1993) dibutuhkan sampel minimum sebanyak 100.

Pada penelitian ini teknik sampling yang digunakan adalah probability sampling, yakni teknik sampling yang memungkinkan anggotaanggota dalam populasi mempunyai peluang atau profitabilitas yang sama untuk dipilih sebagai sampel (Indrawati, 2015). Jumlah anggota sampel dapat ditentukan melalui rumus Taro Yaname dan Slovin, hal ini mengacu pada pendapat Engkos (2011) bahwa "Teknik pengambilan sampel menggunakan rumus dari Taro Yamane dan Slovin apabila populasi sudah diketahui". Adapun rumus tersebut sebagai berikut:

Dimana:

$$
n=\frac{N}{N \cdot d^{2}+1}
$$

$\mathrm{n}=$ Jumlah anggota sampel $; \mathrm{N}=$ Jumlah Populasi ; $d^{2}=$ Presisi

Presisi yang ditetapkan 10\%, maka:

Dengan memasukan kedalam persamaan rumus di atas diperoleh jumlah sample minimum sebagai berikut :

$$
\begin{gathered}
n=\frac{N}{N \cdot d^{2}+1}=\frac{122 \cdot 828}{122.828 \cdot(0,1)^{2}+1} \\
=99,91 \\
=100 \text { orang }
\end{gathered}
$$

Teknik pengumpulan data menggunakan wawancara, observasi dan penyebaran kuesioner dengan menggunakan google form. Metode penelitian merupakan jenis penelitian deskriptif kuantitatif.

\section{Jenis Data}

Data primer didapatkan dari sumber pertama untuk mengambil informasi secara langsung, misalnya dari individu atau perusahaan. Pada penelitian ini data primer didapatkan dari hasil kuesioner yang disebar melalui google form dengan menggunakan media sosial seperti aplikasi chating whatsapp, line, facebook dan instagram kepada masingmasing siswa atau siswi.

Data sekunder didapatkan dari hasil membaca, mempelajari, dan memahami dengan menggunakan media lain yang bersumber dari literatur, bukubuku serta dokumen lainnya (Sugiyono, 2009). Data sekunder yang digunakan pada penelitian berupa data yang berasal dari buku-buku dan literatur yang didapatkan melalui media online seperti jurnal mengenai Pemasaran media 
sosial, Facebook, Twitter, Instagram, Citra merek dan Niat beli.

Pengolahan data primer yang diperoleh dari para responden penelitian menggunakan SEM (Structural Equation Models) dengan bantuan sistem Smart PLS 3.0 untuk mengetahui hubungan-hubungan antar variabel laten. Tujuan dari penggunaan PLS yaitu untuk melakukan prediksi hubungan antar konstruk. Salah satu asumsi yang menjadi sandungan peneliti yaitu asumsi normalitas, dengan menggunakan PLS melalui metode bootstrapping asumsi normalitas tidak akan menjadi masalah karena PLS tidak mensyaratkan minimum sampel (Hussein, 2015).

Terdapat dua jenis dari model SEM diantaranya Outer Model (model pengukuran) dan inner model (model structural). Pada Outer Model terdapat dua pengukuran yaitu model reflektif dan model formatif. Model formatif merupakan penilaian validitas secara tradisional dan tidak dapat digunakan untuk indikator-indikator yang digunakan dengan konsep reliabilitas dan validasi konstruk, sehingga penelitian ini menggunakan model reflektif. Model reflektif dilakukan pertama kali pada pengukuran model PLS SEM. Model pengukuran dinilai dengan menggunakan validitas dan reliabilitas (Hidayat, 2018). Indikator reflektif dilakukan dengan uji convergent validity, discriminant validity, atau dengan Average variance extracted (AVE) dan composite reliability. Menurut Ghozali dan Latan (2015) model structural adalah model yang menghubungkan setiap variabel laten. Pengukuran dengan menggunakan PLS SEM dilakukan dengan menguji RSquared $\left(\mathrm{R}^{2}\right)$ dan uji signifikansi melalui estimasi koefisien jalur.

\section{Convergent Validity}

Konvergen dalam penelitian digunakan untuk menggambarkan hubungan indikator yang mengukur variabel laten. Indikator tersebut diharapkan memiliki nilai korelasi yang tinggi dibandingkan dengan indikator lainnya (Hair et al., 2010). Validitas konvergen memiliki artian bahwa seluruh indikator yang digunakan untuk mewakili dan mendasari suatu variabel laten dapat di demonstrasikan dengan unidimensionalitas yang dilakukan dengan menggunakan nilai rata-rata varian yang diekstraksi (Average variance extracted/AVE). Nilai AVE harus sebesar 0,5 yang artinya setengah dari varian indikator berada dalam ratarata mampu untuk menjelaskan variabel laten. Menurut Ghozali (2012) suatu korelasi dinyatakan valid apabila nilai loading $>0,5$, Dan indikator dinyatakan valid jika nilai outer loadingnya $>0,7$ (Jogiyanto, 2008). Pada penelitian ini nilai loading akan menggunakan nilai outer loading $>0,7$ demi mendapatkan korelasi yang lebih kuat.

\section{Discriminant Validity}

Sedangkan validitas diskriminan menggunakan fornell-larcker dan cross loading. fornell-larcker mensyaratkan suatu variabel laten harus memiliki nilai AVE yang lebih besar dibandingkan dengan nilai $\mathrm{R}^{2}$ tertinggi dari nilai variabel laten lainnya. Kriteria kedua untuk validitas diskriminan yaitu cross loading maka nilai loading dari masingmasing indikator diharapkan lebih tinggi nilainya daripada nilai cross loading (Hidayat, 2018).

\section{Composite Reliability dan Cronbach's Alpha}

Variabel laten dapat dinyatakan memiliki riliabilitas yang baik apabila nilai composite reliability bernilai lebih besar dari 0,7 dan nilai cronbach's 
alpha lebih besar dari 0,7 untuk uji reliabilitas digunakan Cronbach's Alpha. Nilai yang menunjukkan semua indikator dalam model harus memiliki besaran nilai minimal 0,7. Selain itu untuk mengukur reliabilitas digunakan juga nilai PC (Composite reliability) yang diinterpretasikan dengan nilai yang sama dengan Cronbach's Alpha. Setiap masing-masing variabel laten harus menjelaskan varian indikator minimal sebesar $50 \%$, oleh karena itu korelasi absolut antara variabel laten dan indiator harus memiliki nilia outer loading $>0,7$ (Hidayat, 2018).

Uji hipotesis dilakukan dengan bantuan SmartPLS 3.0 dengan menggunakan metode sampling bootstrap, yang bertujuan agar tidak diperlukan lagi asumsi distribusi normal. Menurut Hair Jr et al. (2014), quantiles distribusi normal dapat dijadikan sebagai nilai kritis yang dibandingkan dengan nilai $\mathrm{t}$ empiris. Jika nilai $\mathrm{t}$ empiris $>$ nilai kritis maka koefisien signifikan pada probabilitas error. Uji hipotesis dilakukan dengan ttest pada inner dan outer model.

Menurut Hair Jr et al. (2014) penelitian marketing biasanya menggunakan tingkat signifikansi sebesar 5\%. Dengan tingkat signifikansi 5\% maka nilai t 2-tailed untuk 115 data yaitu sebesar 1.983. Dengan nilai tersebut maka nilai t empiris harus lebih besar dari 1.984 agar dapat disimpulkan bahwa hipotesis diterima. Pada outer model signifikan, disimpulkan indikator dapat digunakan menjadi alat ukur untuk variabel laten, yang selanjutnya dapat diartikan bahwa terdapat pengaruh yang positif dan signifikan dari variabel laten terhadap varibel lainnya.

\section{HASIL DAN PEMBAHASAN Intensitas Penggunaan Media sosial} Hasil analisis karakteristik responden berdasarkan intensitas penggunaan media sosial per hari dapat dilihat pada gambar 2 dibawah ini:

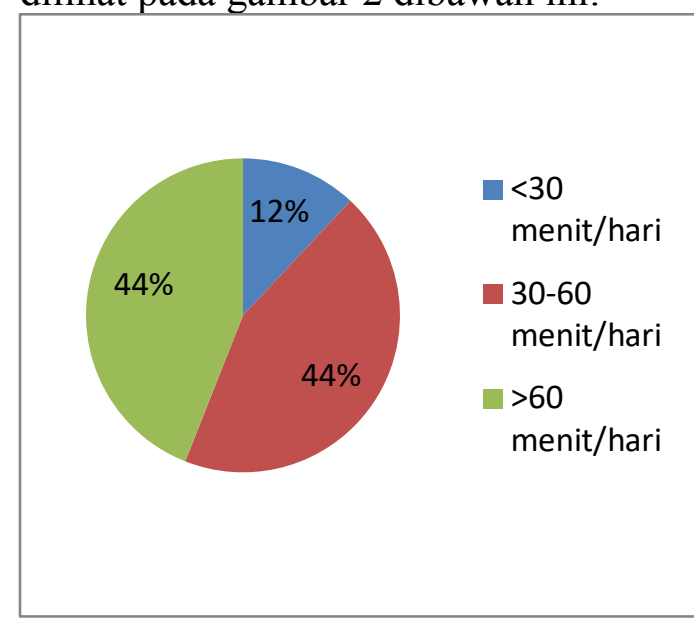

Gambar 2. Lama Penggunaan per hari

Pada gambar 2 ditunjukkan bahwa media sosial sering digunakan sebanyak lebih dari 7 kali perhari dengan lama penggunaan yang imbang diantara 30-60 menit perhari atau lebih dari 60 menit. Selanjutnya terdapat $44 \%$ responden yang menggunakan media sosial sebanyak 4-6 kali sehari. Lama penggunaan media sosial yang paling minim yaitu selama kurang dari 30 menit sehari sejumlah $12 \%$.

\section{Evaluasi Outer Model}

Outer Model digunakan untuk uji validitas dan reliabilitas, koefisien determinasi dan koefisien jalur untuk persamaan. Hasil pengolahan data menggunakan SmartPLS 3.0 adalah sebagai berikut:

Untuk menguji nilai convergent validity maka digunakan nilai dari outer loading. Indikator dapat dikatakan memenuhi convergent validity jika nilai outer loading > 0,7 (Ghozali, 2014). Tabel 1 Convergent Validity merupakan 
hasil pengolahan data hasil iterasi sehingga nilai outer loading setiap variabel sudah memenuhi syarat yaitu $>$ 0,7 :

Tabel 1 Convergent Validity

\begin{tabular}{|c|c|c|c|}
\hline & $\mathrm{BI}$ & PI & SM \\
\hline $\mathrm{x} 1.1$ & & & 0.825 \\
\hline $\mathrm{x} 1.2$ & & & 0.862 \\
\hline $\mathrm{x} 2.2$ & & & 0.731 \\
\hline $\mathrm{x} 2.3$ & & & 0.860 \\
\hline y2.1 & 0.867 & & \\
\hline y2.4 & 0.800 & & \\
\hline $\mathrm{y} 3.3$ & 0.774 & & \\
\hline $\mathrm{z} 1.2$ & & 0.854 & \\
\hline $\mathrm{z} 2$ & & 0.905 & \\
\hline z3 & & 0.929 & \\
\hline $\mathrm{z} 4$ & & 0.885 & \\
\hline
\end{tabular}

Sumber : Data Olahan (2020)

Berdasarkan Tabel 1, diketahui masing-masing variabel penelitian memiliki nilai outer loading $>0,7$ sehingga semua indikator dinyatakan layak untuk digunakan pada penelitian dan dapat dilakukan analisis lebih lanjut. Dari indikator awal yang digunakan untuk variabel media sosial sebanyak 11 butir indikator setelah dilakukan iterasi maka tersisa sebanyak 4 indikator dari dimensi context dan communication. Pada variabel citra merek dari semula memiliki jumlah indikator sebanyak 10 indikator setelah dilakukan pengeleminasian maka sisa indikator sebanyak 4 indikator yang merupakan dimensi dari brand favorable dan brand uniqueness. Variabel niat beli setelah dilakukan iterasi tetap menggunakan dimensi yang utuh yaitu dimensi niat transaksional, niat preferensial, niat referensial dan nilai eksploratif dan tidak ada indikator yang di eleminasi, indikator yang berkurang hanya 1 sehingga jumlah kahir sebanyak 4 indikator.
Tabel 2 Discriminant Validity

\begin{tabular}{llll}
\hline & BI & PI & SM \\
\hline $\mathrm{x} 1.1$ & 0.699 & 0.752 & $\mathbf{0 . 8 2 5}$ \\
\hline $\mathrm{x} 1.2$ & 0.262 & 0.381 & $\mathbf{0 . 8 6 5}$ \\
\hline $\mathrm{x} 2.2$ & 0.217 & 0.381 & $\mathbf{0 . 7 3 1}$ \\
\hline $\mathrm{x} 2.3$ & 0.420 & 0.490 & $\mathbf{0 . 8 6 2}$ \\
\hline $\mathrm{y} 2.1$ & $\mathbf{0 . 8 6 7}$ & 0.603 & 0.585 \\
\hline $\mathrm{y} 2.4$ & $\mathbf{0 . 8 0 0}$ & 0.515 & 0.495 \\
\hline $\mathrm{y} 3.3$ & $\mathbf{0 . 7 7 4}$ & 0.696 & 0.287 \\
\hline $\mathrm{z} 1.2$ & 0.546 & $\mathbf{0 . 8 5 6}$ & 0.501 \\
\hline $\mathrm{z} 2$ & 0.691 & $\mathbf{0 . 9 0 3}$ & 0.684 \\
\hline z3 & 0.624 & $\mathbf{0 . 9 2 9}$ & 0.631 \\
\hline z4 & 0.763 & $\mathbf{0 . 8 8 5}$ & 0.577 \\
\hline Sumber : Data Olahan $(2020)$ &
\end{tabular}

Berdasarkan data Tabel 2 dapat dilihat bahwa masing-masing variabel memiliki nilai cross loading terbesar pada variabel yang dibentuk dibandingkan dengan nilai variabel lainnya. Dari nilai tersebut dinyatakan bahwa indikator-indikator yang digunakan pada penelitian ini merupakan discriminant validity yang baik.

Selain dengan menggunakan nilai cross loading, discriminant validity juga dapat diketahui dengan melihat nilai AVE (Average variance extracted) untuk masing-masing indikator dengan persyaratan nilai $>0,5$ (Ghozali, 2014). Nilai tabel AVE dapat dilihat pada Tabel 3 dibawah ini :

Tabel 3 AVE

\begin{tabular}{ll}
\hline & $\begin{array}{l}\text { Average } \\
\text { Extracted (AVE) }\end{array}$ \\
\hline BI & 0.664 \\
\hline PI & 0.798 \\
\hline SM & 0.674 \\
\hline mber : Data Olahan (2020)
\end{tabular}

Hasil Tabel 3 tersebut menunjukkan bahwa setiap variabel yang digunakan untuk penelitian memiliki discriminant validity yang baik. 


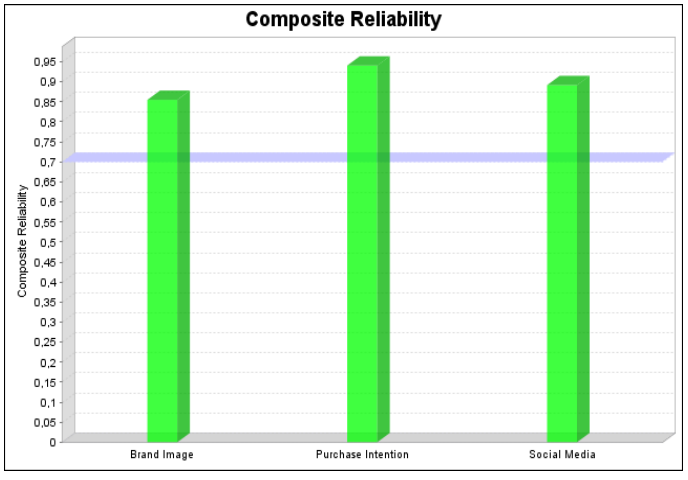

Gambar 3. Composite Reliability

Sumber : Data Olahan (2020)

Setiap variabel memiliki nilai composite reliability diatas batas standar PLS atau $>0,6$. Sehingga data menunjukkan bahwa seluruh variabel memiliki nilai tingkat reliabilitas yang tinggi. Uji reliabilitas dengan composite reliability dapat diperkuat dengan menggunakan Cronbach's Alpha. Variabel dapat dinyatakan reliabel jika memenuhi Cronbach's Alpha sebesar > 0,7 (Eisingerich \& Rubera, 2010). Gambar 4 hasil Cronbach's Alpha dari masing-masing variabel :

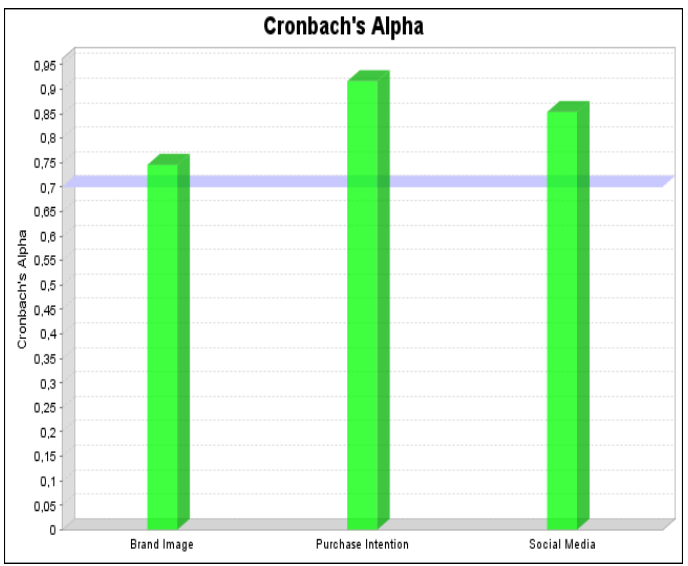

Gambar 4. Cronbach's Alpha

Sumber : Data Olahan (2020)

Berdasarkan grafik yang ditunjukkan setiap variabel sudah melampaui batas layak, walaupun pada variabel revisit intention tepat berada pada garis batas namun tetap melampaui nilai 0,7 . Sehingga data pada penelitian ini dinyatakan reliabel.
Pada penelitian ini akan dijelaskan mengenai inner model yang didalamnya terdapat pembahasan evaluasi yang menggunakan $\mathrm{R}^{2}$ untuk variabel dependen dan nilai path coefficient untuk vairabel independen. Gambar 5 menunjukkan hasil output dari SmartPLS :

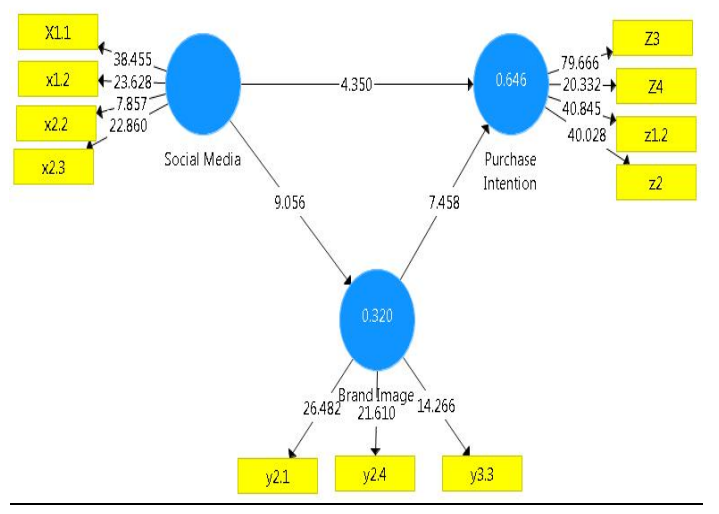

Gambar 5. Inner Model

Sumber : Data Olahan (2020)

Kemudian signifikansi dinilai dengan melihat nilai $t$-statistik dari setiap path yang ditunjukkan pada tabel 4 merupakan hasil dari inner model yang diolah menggunakan sistem PLS 3.3.

Tabel 4. t-statistik

\begin{tabular}{llllll}
\hline & $\begin{array}{l}\text { Original } \\
\text { Sample } \\
(\mathrm{O})\end{array}$ & $\begin{array}{l}\text { Sample } \\
\text { Mean } \\
(\mathrm{M})\end{array}$ & $\begin{array}{l}\text { Standard } \\
\text { Deviation } \\
(\mathrm{STDEV})\end{array}$ & $\begin{array}{l}\text { T } \\
\text { Statistics } \\
(\mid \mathrm{O} / \mathrm{STD} \\
\mathrm{EV} \mid)\end{array}$ & $\begin{array}{l}\mathrm{P} \\
\text { Values }\end{array}$ \\
\hline $\begin{array}{l}\mathrm{BI}> \\
\mathrm{PI}\end{array}$ & 0.529 & 0.526 & 0.071 & 7.458 & 0.000 \\
\hline $\mathrm{SM}>$ & & & & \\
$\mathrm{BI}$ & 0.565 & 0.573 & 0.062 & 9.056 & 0.000 \\
\hline $\mathrm{SM}>$ & & & & \\
$\mathrm{PI}$ & 0.376 & 0.376 & 0.086 & 4.350 & 0.000 \\
\hline \multicolumn{5}{r}{ Sumber : Data Olahan $(2020)$}
\end{tabular}

Hubungan antara media sosial dan citra merek adalah signifikan dengan $\beta=0.565$ dan nilai $\mathrm{t}=9.056>\mathrm{t}$ tabel 1.661 dengan signifikansi sebesar $5 \%$ yang menunjukkan bahwa media sosial memiliki pengaruh langsung dan signifikan terhadap citra merek. Oleh karena hasil data analisis menunjukkan 
adanya hubungan yang signifikan maka setiap ada peningkatan media sosial maka akan mempengaruhi peningkatan citra merek.

Hubungan antara media sosial dan niat beli adalah signifikan dengan $\beta$ $=0.376$ dan nilai $\mathrm{t}=4.350>\mathrm{t}$-tabel 1.661 dengan signifikansi sebesar 5\% yang menunjukkan bahwa media sosial memiliki pengaruh langsung dan signifikan terhadap niat beli. Dapat diartikan jika terdapat peningkatan pada media sosial maka akan niat beli juga akan meningkat.

Hubungan antara citra merek dan niat beli adalah signifikan dengan $\beta$ $=0.503$ dan nilai $\mathrm{t}=5.991>\mathrm{t}$-tabel 1.661 dengan signifikansi 5\%. Hal ini menunjukkan bahwa terdapat pengaruh langsung dan signifikan dari citra merek terhadap niat beli. Analisis juga dapat diartikan jika terdapat peningkatan pada citra merek maka akan terjadi peningkatan.

Hubungan antara media sosial dengan niat beli melalui mediasi citra merek adalah signifikan dengan $\beta=$ 0.529 dan nilai $\mathrm{t}=7.458>\mathrm{t}$-tabel 1.661 dengan signifikansi $5 \%$. Hal ini menunjukkan bahwa terdapat pengaruh langsung dan signifikan dari citra merek terhadap niat beli. Analisis juga dapat diartikan arah hubungan antara media sosial terhadap niat beli adalah positif.

\section{Pengaruh Media Sosial terhadap Citra Merek}

Pengaruh media sosial terhadap citra merek memiliki pengaruh yang paling besar dibandingkan dengan variabel lainnya yang diteliti pada penelitian ini, sehingga berdasarkan hasil analisis data penelitian pada hipotesis pertama yang diajukan oleh penelitian ini, data tersebut membuktikan bahwa keterlibatan media sosial official dapat mempengaruhi citra merek dari objek tersebut. Keterangan tersebut dapat diperkuat dengan persamaan pada penelitian sebelumnya milik (BİLGİN, 2018) yang menyatakan bahwa terdapat hubungan positif antara media sosial dengan citra merek. (BILGIN, 2018) juga menyatakan bahwa kegiatan promosi melalui media sosial merupakan kunci dari keberhasilan peningkatan pada citra merek.

Faktor-faktor yang mempengaruhi Citra merek berasal dari indikator media sosial yang digunakan pada penelitian ini. Indikator yang digunakan untuk mengetahui pengaruh media sosial terhadap citra merek yaitu berasal dari dimensi context dan communication. Dimensi context merupakan pernyataan yang dibuat supaya pesan yang disampaikan dapat dengan mudah dimengerti oleh penerima (Solis, 2010). Context yang digunakan biasanya merupakan caption yang menarik setiap memposting sebuah konten. Sebuah objek dalam context juga menyediakan berbagai informasi penting dan menarik secara berkala di berbagai media sosial official terutama pada Instagram.

Dimensi communication memacu penerima untuk dapat berinteraksi atau merespon pemberi pesan sehingga dapat dipastikan bahwa informasi yang disampaikan benar dapat diterima (Solis, 2010). Dengan menggunakan dimensi tersebut dapat meningkatkan citra universitasnya akan dengan mudah disebarkan. Selain itu dengan menggunakan media sosial dapat dengan mudah memberikan informasi mengenai keunggulankeunggulan yang dimiliki sehingga para pengikut media sosial dapat mengenali objek tersebut dengan lebih baik lagi.

Dalam konteks dimensi komunikasi dalam mengembangkan citra merek, peran admin setiap media sosial sangat berpengaruh besar dalam 
proses penyampaian informasi. Oleh karena itu dibutuhkan admin yang secara aktif memberikan informasi dan juga menjawab setiap pertayaan yang dilontarkan para pengguna media sosial terutama Instagram.

Hasil analisis data menunjukkan bahwa media sosial memiliki nilai yang baik untuk mempengaruhi citra merek, sehingga media sosial yang dikelola harus responsif dan memberikan informasi yang up to date.

\section{Pengaruh Media Sosial terhadap Niat Beli}

Menurut hasil penelitian untuk menjawab tujuan penelitian yang dirumuskan, pengaruh Media sosial terhadap Niat beli menghasilkan pengaruh positif. sehingga berdasarkan hasil analisis data penelitian pada hipotesis ke dua yang diajukan oleh penelitian ini, data tersebut membuktikan bahwa keterlibatan media sosial official yang saat ini dikelola langsung oleh universitas tersebut dapat mempengaruhi niat beli para siswa di Kota Bandung. Pernyataan tersebut dapat diperkuat dengan penelitian sebelumnya milik Wang et al. (2015) yang menyatakan para pengikut media sosial sebuah brand akan cenderung memilih brand yang mereka ikuti tersebut.

Sesuai pernyataan milik Wang et al. (2015) saat ini para calon mahasiswa yang ingin melanjutkan jenjang pendidikan tinggi, telah mengikuti media sosial pada universitas dan memantau informasi-informasi terbaru yang dibagikan melalui media sosial. Sehingga kerap ditemukan para calon mahasiswa yang menanyakan prosedur pendaftaran melalui media sosial seperti instagram.

Sebuah universitas dapat memanfaatkan media sosial lebih dari sekedar memberikan informasi mengenai prosedur pendaftaran, tapi dapat juga digunakan sebagai pemicu calon mahasiswa memiliki niat untuk mendaftar (niat beli) di universitas. Media sosial dapat membantu memberikan informasi yang dibutuhkan para calon mahasiswa untuk mengetahui lebih banyak informasi mengenai universitas. Fitur yang digunakan biasanya merupakan feeds Instagram yang fokus dalam membentuk iklan melalui media sosial dan menggunakan media sosial lebih efektif lagi karena terbukti memiliki nilai cukup besar yang dapat berguna sebagai alat untuk membentuk presepsi calon mahasiswa dan mempengaruhi niat beli terhadap universitas. Sesuai dengan pernyataan Jocz dan Quelch (2008) yang telah mengakui bahwa teknologi telah menjadi yang komponen utama dalam memperluas pasar dan telah menetapkan seluruh strategi pemasaran dari seputar akses global ke teknologi. Pada waktu bersamaan, iklan dan promosi sering fokus pada psikologis, emosional, dan faktor-faktor sosial yang mempengaruhi perilaku konsumen, elemen yang harus dimasukkan ke dalam pemasaran berbasis teknologi.

\section{Pengaruh Citra Merek terhadap Niat Beli}

Hasil dari analisis faktor pada variabel Citra merek menghasilkan faktor-faktor penting dalam hubungan dengan Niat beli siswa SMA di Kota Bandung. Faktor Citra merek yang dimiliki Kota Bandung memiliki peranan penting dalam penyebab siswa memilih universitas sebagai universitas tujuan untuk menempuh pendidikan tinggi melalui faktor brand favorable dan brand uniqueness. Dari tiga dimensi yang disebutkan oleh (K. Keller, 2003) yaitu brand strength, brand favorability dan brand uniqueness, dimensi-dimensi tersebut dapat mempengaruhi niat 
pembelian yang dirasakan oleh para siswa di Kota Bandung. Sesuai dengan pernyataan (Wang et al., 2015) bahwa citra merek memiliki dampak positif terhadap niat beli. Citra merek yang sudah dibangun universitas saat ini terbukti dilakukan dengan baik karena masuk dalam nominasi 100 universtias terbaik di Indonesia.

Dimensi brand favorabel yang dimiliki universitas berkaitan dengan citra universitas yang merupakan universitas elite dengan fasilitas yang terawat dengan baik, selain itu memiliki pelayanan yang professional dan juga memiliki lokasi strategis sehingga akses menuju lokasi menjadi mudah dijangkau. Pada dimensi brand uniqueness berfokus pada pembeda dengan universitas lainnya, seperti membandingkan dengan universitas swasta lainnya di Kota Bandung, selain itu track record lulusan universitas yang saat ini memiliki karir cemerlang, dan mudah dalam mendapatkan pekerjaan atau memiliki ilmu memadai untuk menjadi entrepreneur. Bagi sebagian besar universitas, citra merek mungkin tidak menjadi masalah. Mereka telah membangun reputasi selama bertahuntahun, didukung oleh prestasi dan ketenaran alumni.

\section{Pengaruh Media Sosial terhadap Niat Beli dengan Mediasi Citra Merek}

Hasil dari analisis faktor pada variabel Media sosial menghasilkan faktor-faktor penting dalam hubungan dengan Niat beli. Faktor Media sosial yang dimiliki universitas memiliki peranan penting dalam penyebab calon mahasiswa memilih universitas sebagai tempat tujuan pendidikan melalui faktor Citra merek. Hasil penelitian ini menunjukkan hubungan yang negatif signifikan diantara variabel media sosial terhadap niat beli melalui citra merek. Sehingga dapat disimpulkan bahwa penyampaian citra merek universitas melalui media sosial belum begitu baik dan belum menyebabkan meningkatnya niat beli. Berkebalikan dengan penelitian milik Wang et al. (2015) yang meneliti variabel pengaruh media sosial terhadap citra merek dan niat beli yang menunjukkan bahwa Wang et al. (2010) media sosial secara langsung dapat mempengaruhi niat beli secara positif dan signifikan, namun media sosial dengan mediator citra merek terhadap niat beli menghasilkan efek negatif signifikan sehingga jika media sosial dimanipulasi secara eksperimental sehingga variabel media sosial dapat mengurangi niat beli secara tidak langsung ketika media sosial hanya melalui citra merek hal ini juga penyebab kemungkinan terjadi karena adanya variabel lain yang tidak masuk dalam penelitian. Seperti pada penelitian milik yang menyertakan variabel lainnya yaitu brand awareness sebagai mediator untuk mengetahui pengaruh brand niat beli. Media sosial digunakan sebagai sarana hiburan dan menyampaikan segala jenis informasi, sehingga konten yang disajikan harus beragam agar para pengikut merasa terhibur. Oleh karena itu dimungkinkan fakor lainnya yang dapat memoderator hubungan antara media sosial terhadap niat beli.

Minat beli atau niat beli dapat terbentuk karena sikap orang lain, dimana sikap orang lain mengurangi alternatif yang disukai seseorang akan tergantung pada dua hal yaitu intensitas sikap negatif orang terhadap alternatif yang disukai konsumen dan motivasi konsumen untuk menuruti keinginan orang lain penyampaian media sosial melalui citra merek dapat memungkinkan sikap negatif tersebut muncul sehingga dapat mempengaruhi minat beli. Penelitian serupa yang menyatakan terdapat efek negatif dari 
media sosial terhadap niat beli yaitu milik Nafisah (2018) yang menyatakan bahwa dimensi communication dari variable media sosial menunjukkan angka negatif sehingga dapat menurunkan niat beli.

Media sosial sangat kuat dalam kemampuannya untuk memfasilitasi komunikasi. Setiap orang memiliki kebutuhannya sendiri ketika menggunakan media sosial, selain dari berbagi informasi edukatif juga dapat digunakan untuk menawarkan item dan layanan. Ini adalah fitur yang banyak digunakan oleh banyak perusahaan untuk menawarkan barang dan layanan selain informasi yang dapat menambah pengetahuan bagi penggunanya, yang dimaksudkan untuk tujuan branding. Namun, ketika strategi meningkatkan citra merek tidak sesuai denga menggunakan media sosial, mungkin media lain lebih cocok, seperti media elektronik, media cetak, atau melalui strategi PR lainnya saluran seperti acara offline, CSR, publisitas, dan lain-lain.

\section{PENUTUP}

\section{Kesimpulan}

Dari pembahasan diatas dapat disimpulkan bahwa hasil dari sebuah hipotesis pertama (H1) adalah terdapat pengaruh positif dari pemasaran media sosial terhadap citra merek, ada hipotesis kedua (H2) terdapat pengaruh positif dari citra merek terhadap niat beli Generasi Z, dan pada hipotesis ketiga (H3) terdapat pengaruh positif dari media sosial terhadap niat beli Generasi $\mathrm{Z}$ dengan mediasi citra merek.

\section{DAFTAR PUSTAKA}

Abed, S. S., Dwivedi, Y. K., \& Williams, M. D. (2015). Social media as a bridge to e-commerce adoption in SMEs: A systematic literature review. The Marketing Review. https://doi.org/10.1362/1469347 $15 \times 14267608178686$

Ajini, A. (2012). How The Customer's purchase Intention Efected. John Willey and Sons.

Aklani, S. (2016). Pemanfaatan Social media Sebagai Media Promosi Mahasiswa PadaMatakuliah Kewirausahaan di Universitas Internasional Batam. Konferensi Nasional PKM Dan CSR Ke 2.

Angkie, N. (2019). Pengaruh Social Media Marketing terhadap Brand Equity pada Brand Fashion ZARA, H\&M, PULL\&BEAR, dan STRADIVARIUS di Surabaya. Agora.

Arslan, F. M., \& Altuna, O. K. (2010). The effect of brand extensions on product brand image. Journal of Product and Brand Management.

https://doi.org/10.1108/1061042 1011046157

BİLGIN, Y. (2018). The Effect of Social Media Marketing Activities on Brand Awareness, Brand Image, and Brand Loyalty. Business \& Management Studies: An International Journal, 6(1). https://doi.org/10.15295/v6il.22 9

Boyd, D. M., \& Ellison, N. B. (2007). Social network sites: Definition, history, and scholarship. Journal of Computer-Mediated Communication. https://doi.org/10.1111/j.10836101.2007.00393.X

Castronovo, C., \& Huang, L. (2012). Social Media in an Alternative Marketing Communication Model. Journal of Marketing Development and Competitiveness. 
Chauhan, K., \& Pillai, A. (2013). Role of content strategy in social media brand communities: A case of higher education institutes in India. Journal of Product and Brand Management.

https://doi.org/10.1108/1061042 1311298687

Chi, H. K., Yeh, H. R., \& Huang, M. W. (2009). The Influences of advertising endorser, brand image, brand equity, price promotion, on purchase intention- the mediating effect of advertising endorser. The Journal of Global Business Management.

Cilliers, E. J. (2017). THE CHALLENGE OF TEACHING GENERATION Z. PEOPLE: International Journal of Social Sciences.

https://doi.org/10.20319/pijss.20 17.31.188198

Dolot, A. (2018). The characteristics of Generation Z. E-Mentor. https://doi.org/10.15219/em74.1 351

Duan, W., Gu, B., \& Whinston, A. B. (2008). The dynamics of online word-of-mouth and product sales-An empirical investigation of the movie industry. Journal of Retailing.

https://doi.org/10.1016/j.jretai.20 08.04.005

Eisingerich, A. B., \& Rubera, G. (2010). Drivers of brand commitment: A cross-national investigation. Journal of International Marketing. https://doi.org/10.1509/jimk.18.2 .64

Engkos, R. (2011). Cara Menggunakan dan Memakai Path Analysis. CV. Alfabeta.

Farivar, S., Turel, O., \& Yuan, Y.
(2017). A trust-risk perspective on social commerce use: an examination of the biasing role of habit. Internet Research. https://doi.org/10.1108/IntR-062016-0175

Ferdinand, A. (2007). Metode Penelitian Manajemen. Universitas Diponegoro.

Fraenkel, J. R., Wallen, N. E., \& Hyun, H. (1993). How to design and evaluate research in education (2nd ed.). McGraw-Hill Inc.

Ghosh, A. (1990). Retail Management. Drydden Press.

Ghozali. (2014). Structural Equation Modeling Metode Alternatif dengan Partial Least Squares (PLS) (4th ed.). Badan Penerbit Universitas Diponegoro.

Ghozali and Latan. (2015). Partial Least Squares: Concepts, Techniques and Applications using SmartPLS 3 (2nd ed.). Diponegoro University Press.

Ghozali, I. (2012). Aplikasi Analisis Multivariate dengan Program IBM SPSS. Universitas Diponegoro.

Gogoi, B. J. (2013). Study of Antecedents of Purchase Intention and its Effect on Brand Loyalty of Private Label Brand of Apparel. International Journal of Sales and Marketing Management Research and Development.

Hair, J. F., Black, W. C., Babin, B. J., \& Anderson, R. E. (2010). Multivariate Data Analysis. Pearson Prentice Hall.

Hair Jr, J. F., Sarstedt, M., Hopkins, L., \& G. Kuppelwieser, V. (2014). Partial least squares structural equation modeling (PLS-SEM). European Business Review, 26(2), 106-121. https://doi.org/10.1108/EBR-10- 
2013-0128

Hidayat, A. (2018). PLS SEM: Pengukuran Kecocokan Model (Inner dan Outer). Statistikian.

Hussein, A. S. (2015). Penelitian Bisnis dan Manajemen Menggunakan Partial Least Squares (PLS) dengan smartPLS 3.0 (Modul Ajar). Fakultas Ekonomi Dan Bisnis Universitas Brawijaya.

Indrawati. (2015). Metode Penelitian Manajemen dan Bisnis. Konvergensi Teknologi Komunikasi dan Informasi. PT. Refika Aditama.

Jocz, K. E., \& Quelch, J. A. (2008). An exploration of marketing's impacts on society: A perspective linked to democracy. In Journal of Public Policy and Marketing.

https://doi.org/10.1509/jppm.27. 2.202

Jogiyanto. (2008). Metodologi Penelitian Sistem Informasi. CV Andi Offset.

Kawa, L. W., Rahmadiani, S. F., \& Kumar, S. (2013). Factors Affecting Consumer DecisionMaking: A Survey of YoungAdults on Imported Cosmetics in Jabodetabek, Indonesia. The SIJ Transactions on Advances in Space Research \& Earth Exploration, 1(3), 17-22. https://doi.org/10.9756/SIJASRE E/V1I3/0105420101

Keller, K. (2003). Strategic Brand Management, Building Measurement and Managing Brand Equity. Upper Sadle River.

Keller, K. L. (2009). Building strong brands in a modern marketing communications environment. Journal of Marketing Communications, 1339-155. https://doi.org/10.1080/1352726
0902757530

Khan, A. S., \& Jan, F. (2015). The Study of Organization Commitment and Job Satisfactionamong Hospital Nurses. A Survey of District Hospitals of DeraIsmail Khan. Global Journal of Management and Business Research.

Kim, D. J., Ferrin, D. L., \& Rao, H. R. (2008). A trust-based consumer decision-making model in electronic commerce: The role of trust, perceived risk, and their antecedents. Research Collection Lee Kong Chian School Of Business.

Kim, S., \& Park, H. (2013). Effects of various characteristics of social commerce (s-commerce) on consumers' trust and trust performance. International Journal of Information Management.

https://doi.org/10.1016/j.ijinfom gt.2012.11.006

Kircova, İ., Enginkaya, E., \& Y1lmaz, H. (2015). Influence of consumers' self-brand connections on purchase intentions. Annual International Conference on Social Sciences.

Kurcova, İ., Yaman, Y., \& Gizem Köse, Ş. (2019). Instagram, Facebook or Twitter: Which Engages Best? A Comparative Study of Consumer Brand Engagement and Social Commerce Purchase Intention. European Journal of Economics and Business Studies. https://doi.org/10.2478/ejes2018-0031

kominfo.go.ia. (2013). Kominfo : Pengguna Internet di Indonesia 63 Juta Orang. Kominfo.

Kotler, P., \& Keller, K. (2016). Marketing Management. Pearson Pretice Hall, Inc. 
Kotler, P. (2004). Marketing Management (The Millen). Prentice Hall.

Kotler, P., \& Armstrong, G. (2010). Principles of marketing. Pearson Prentice Hall.

Kupperschmidt, B. R. (2000). Multigeneration employees: strategies for effective management. The Health Care Manager.

https://doi.org/10.1097/0012645 0-200019010-00011

Küster, I., \& Hernández, A. (2012). Brand impact on purchase intention. An approach in social networks channel. Economics and Business Letters. https://doi.org/10.17811/ebl.1.2. 2012.1-9

Lin, C. T., \& Shii, C. S. (2018). The Important of Brand Image on Customer Purchase Attitude: A Case Study of E-Commerce in Taiwan. Studies in Business and Economics, 91-104.

Mangold, W. G., \& Faulds, D. J. (2009). Social media: The new hybrid element of the promotion mix. Business Horizons. https://doi.org/10.1016/j.bushor. 2009.03.002

Miller, K. (2009). Organizational Communication: Approaches and Processes (6th ed.). Wadsworth Publishing Company.

Nafisah. (2018). Pengaruh Strategi Promosi Melalui Social Media terhadap Minat Beli Konsumen. Sekolah Tinggi Ilmu Ekonomi Widya Wiwaha Yogyakarta.

Palmer Adrian. (2001). Principles Of Services Marketing (Third). McGraw- Hill Companies.

Pongpaew, W., Speece, M., \& Tiangsoongnern, L. (2017). Social presence and customer brand engagement on Facebook brand pages. Journal of Product and Brand Management. https://doi.org/10.1108/JPBM08-2015-0956

Schivinski, B., \& Dabrowski, D. (2014). The effect of social media communication on consumer perceptions of brands. Journal of Marketing Communications.

Shah, et al. (2012). The Impact of Brands on Consumer Purchase Intentions. Asian Journal of Business Management.

Sidorcuka, I., \& Chesnovicka, A. (2017). Methods of Attraction and Retention of Generation Z Staff. $\quad C B U$ International Conference Proceedings. https://doi.org/10.12955/cbup.v5 .1030

Singh, A. P., \& Dangmei, J. (2016). UNDERSTANDING THE GENERATION $Z$ : $\quad$ THE FUTURE WORKFORCE. South -Asian Journal of Multidisciplinary Studies.

Solis, B. (2010). Engage: The Complete Guide for Brands and Businesses to Build, Cultivate, and Measure Success in the New Web. Wiley.

Sudarwati, W., \& Tikwalau, D. E. (2014). Faktor-Faktor Yang Mempengaruhi Siswa-Siswa SMU/SMK Terhadap Keputusan Pemilihan Perguruan Tinggi Swasta. Dasar-Dasar Manajemen, $\quad 1(1)$. https://doi.org/https://doi.org/10. 24853/jisi.1.1.\%25p

Sugiyono. (2009). Metode Penelitian Kuantitatif, Kualitatif dan R\&D. Alfabeta.

Tariq, M. I., Rafay Nawaz, M., Nawaz, M. M., \& Butt, H. A. (2013). Customer Perceptions about Branding and Purchase 
Intention: A Study of FMCG in an Emerging Market. J. Basic. Appl. Sci. Res.

Tih, S., \& Lee, K. H. (2013). Perceptions and predictors of consumers' purchase intentions for store brands: Evidence from Malaysia. Asian Journal of Business and Accounting.

Van Dijk, J. A. G. . (2006). The Network Society. SAGE Publications.

Wang, F., Hu, F., \& Yu, L. (2010). The Application of Customer Relationship Management in Investment Banks. Asian Social Science.

https://doi.org/10.5539/ass.v6n1 $0 \mathrm{p} 178$

Wang, H. W., Wu, Y. C. J., \& Dong, T. P. (2015). Exploring the impacts of social networking on brand image and purchase intention in cyberspace. Journal of Universal Computer Science.

Wang, X., Yu, C., \& Wei, Y. (2012). Social Media Peer Communication and Impacts on Purchase Intentions: A Consumer Socialization Framework. Journal of Interactive Marketing. https://doi.org/10.1016/j.intmar. 2011.11.004

Winer, R. S. (2009). New Communication Approaches in Marketing: Issues and Research Directions. Journal of Interactive Marketing, 23, 108117.

Żarczyńska-Dobiesz, A., \& Chomątowska, B. (2014). Pokolenie ,Z" na rynku pracy wyzwania dla zarządzania zasobami ludzkimi. Prace Naukowe Uniwersytetu Ekonomicznego We Wroctawiu. https://doi.org/10.15611/pn.2014
.350 .36

Zeeshan, Z. (2013). The impact of mobile service attributes on males' and females' purchase decision, Management \& Marketing Challenges for the Knowledge Society. Management Şi Marketing (Bucureşti), 8(4), 669-682. 